\title{
Let's Standardize the Definition of Concussion and Get Reliable Incidence Data
}

Currently, there is major interest in the issue of concussions $^{1-4}$ because it is now recognized that concussions are brain injuries, and even a single concussion can produce permanent sequelae ${ }^{5}$. Also, most experts agree that a second head injury during the recovery phase after a concussion can lead to death or permanent major disability, a condition called the second impact syndrome ${ }^{6}$. Other significant post concussion problems include permanent memory loss, depression and personality change ${ }^{5}$. Unfortunately, there is a lack of uniformity about the definition of concussion and about management such as the need to seek medical attention after a concussion. The problems about definition have made it difficult to evaluate the reliability of epidemiological data, especially regarding the incidence of concussion. Although there have been attempts by rehabilitation specialists, sports medicine specialists and the World Health Organization to clarify the definition and treatment of this condition, there is still much confusion and lack of uniformity of definition as indicated so clearly by the paper by Ryu and colleagues in this edition of the Journal ${ }^{7}$.

One of the first attempts to improve the definition of this condition was made in 1966 by the Congress of Neurological Surgeons $^{8}$, and another was made in 1993 by the American Congress of Rehabilitation Medicine ${ }^{9}$. The latter organization defined mild traumatic brain injury (MTBI) based on several criteria such as a Glasgow Coma Scale (GCS) of 13-15. The World Health Organization commissioned excellent studies of the incidence of MTBI based on this definition ${ }^{10}$, and there are continuing efforts to clarify some of the criteria in an attempt to make it more useful ${ }^{11}$. However, the MTBI definition is cumbersome and is infrequently used in Canada, as discovered by Ryu et $\mathrm{al}^{7}$ who found that the GCS, an essential component of the definition of MTBI, was documented in only one-third of cases. Thus, most practitioners involved in the diagnosis of concussion view the inclusion of the GCS as unnecessary and irrelevant in the management of patients with concussion.

Other organizations have preferred to use the older term concussion for these less severe head injuries. Indeed, concussion has always been a diagnostic category in the International Classification of Diseases which is used by most hospitals in the world for the categorization of diseases and injuries. Concussion is also the principal diagnostic term used by sports medicine organizations. Furthermore, useful guidelines about the management of concussions have appeared as position statements from respected sports medicine organizations such as the Canadian Academy of Sport Medicine. Sports medicine has been in an ideal position to take the lead in studying concussion because of the alarmingly high incidence of single and repeated concussions in certain contact sports such as hockey and football. In my opinion, the definition of concussion developed by the Concussion in Sport Group can serve for all causes of concussion. The definition has been carefully crafted by participants at three recent international meetings of experts in 2002, 2004 and 2008. The position statements from the first two meetings have been published ${ }^{12,13}$, and the third is expected shortly. Several distinguished Canadian physicians and surgeons have been leaders in this Group, including Mark Aubry, Karen Johnston and Willem Meeuwisse. Unfortunately, the sports medicine definition of concussion is not precisely the same as MTBI. As indicated above, the latter includes a GCS of 13-15, and includes patients with focal neurological deficits. Unfortunately, the position on concussions from the sports medicine groups has not been officially adopted by practitioners in other fields, including neurologists, neurosurgeons and family doctors, groups that are often called upon to diagnose and manage concussions. I strongly agree with the suggestion made by $\mathrm{Ryu}$ et $\mathrm{al}^{7}$ that knowledge of concussion should be disseminated to all physicians. I would add the recommendation that all physician groups should adopt the definition and management guidelines developed by the sports medicine groups.

Ryu et $\mathrm{al}^{7}$ also correctly indicated that most patients with concussion are no longer admitted to hospital, and therefore, data on the current incidence of concussion has to be based on visits to emergency departments and practitioners' offices rather than hospital admissions. However, the authors limited their survey to family physicians' offices, whereas patients with concussions are seen by a variety of practitioners. Also, their study was based on 2001 data, and therefore was prior to the deployment of the National Ambulatory Care System that might have provided more comprehensive data. Indeed, only 19 physicians' offices participated in their survey, which is inadequate for a surveillance study of this type. The authors also found that misdiagnosis is a factor for underestimating the true incidence of MTBI or concussion. To this should be added the patients who refuse to see a doctor or who are not advised to do so after a concussion. In addition, under-reporting is well recognized in concussions in sports ${ }^{14}$. The authors reported an incidence of MTBI of about 600 cases per 100,000 population based on age over 16. This retrospective study has many limitations as acknowledged by the authors, and must be corroborated by a comprehensive, broadly based prospective study of patients of all age groups seen in emergency departments and physicians' offices.

In conclusion, the paper by Ryu et $\mathrm{al}^{7}$ clearly indicates the need for clarity and uniformity in the terminology used by practitioners to document concussions. A multidisciplinary panel should be assembled to consider adopting the definition and management of concussion used in sports medicine and to 
conduct a comprehensive, prospective survey of concussion in all age groups from all causes. Head injuries are very important to individuals and to society because of the large number sustaining a concussion and their frequent and serious long term affects. Prevention and management of concussion are hampered by lack of a universally accepted definition and lack of comprehensive incidence data.

Charles H. Tator

Toronto, Ontario

\section{REFERENCES}

1. Cusimano M. Canadian minor hockey participants' knowledge about concussion. Can J Neurol Sci. 2009;36:315-20.

2. Ackery A, Provvidenza C, Tator C. Concussion and other head injuries in hockey: compliance with return to play advice and follow-up status. Can J Neurol Sci. 2009; 36:207-12.

3. Tator $\mathrm{CH}$. Concussions are brain injuries and should be taken seriously. Can J Neurol Sci. 2009;36(3):269-70.

4. Tator $\mathrm{CH}$, editor. Catastrophic injuries in sports and recreation, causes and prevention: a Canadian study. Toronto: University of Toronto Press; 2008.

5. De Beaumont L, Theoret H, Mongeon D, Messier J, Leclerc S, Tremblays, et al. Brain function decline in healthy retired athletes who sustained their last sports concussion in early adulthood. Brain. 2009;132(Pt 3):695-708.

6. Cantu RC. Second-impact syndrome. Clin Sports Med. 1998;17: $37-44$.

7. Ryu WHA, Feinstein A, Colantonio C, Streiner DL, Dawson DR. Early identification of mild TBI in Ontario. Can J Neurol Sci. $2009 ; 36: 429-35$.
8. Congress of Neurological Surgeons. Committee on Head Injury Nomenclature: Glossary of Head Injury. Clin Neurosurg. 1966; $12: 386-94$

9. Definition of mild traumatic brain injury. Developed by the Mild Traumatic Brain Injury Committee of the Head Injury Interdisciplinary Special Interest Group of the American Congress of Rehabilitation Medicine. J Head Trauma Rehab. 1993;8:86-7.

10. Cassidy JD, Carroll LJ, Peloso PM, Borg J, von Holst H, Holm L, et al. Incidence, risk factors and prevention of mild traumatic brain injury: results of the WHO Collaborating Centre Task Force on Mild Traumatic Brain Injury. J Rehabil Med. 2004; 43 Suppl:28-60.

11. Ruff RM, Iverson GL, Barth JT, Bush SS, Broshek DK. Recommendations for diagnosing a mild traumatic brain injury: a National Academy of Neuropsychology education paper. Arch Clin Neuropsychol. 2009;24:3-10.

12. McCrory P, Johnston K, Meeuwisse W, Aubry M, Cantu R, Dvorak $\mathrm{J}$, et al. Summary and agreement statement of the 2nd International Conference on Concussion in Sport, Prague 2004. Br J Sports Med. 2005;39:196-204.

13. Aubry M, Cantu R, Dvorak J, Graf-Baumann T, Johnston K, Kelly $\mathrm{J}$, et al. Summary and agreement statement of the First International Conference on Concussion in Sport, Vienna 2001. Recommendations for the improvement of safety and health of athletes who may suffer concussive injuries. Br J Sports Med. 2002;36:6-10.

14. Williamson IJ, Goodman D. Converging evidence for the underreporting of concussions in youth ice hockey. Br J Sports Med. 2006;40:128-32; discussion 128-32. 